\title{
Successful Use of Steroids and Ureteric Stents in 24 Patients with Idiopathic Retroperitoneal Fibrosis: A Retrospective Study
}

\author{
Andrew C. Fry ${ }^{a}$ Sadmeet Singh ${ }^{b}$ Smita S. Gunda ${ }^{a} \quad$ Greg B. Boustead ${ }^{b}$ \\ Damian C. Hanbury ${ }^{b}$ Thomas A. McNicholas ${ }^{b}$ Ken Farrington ${ }^{a}$

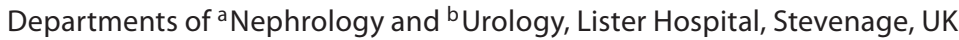

\section{Key Words}

Retroperitoneal fibrosis · Steroids • Stents • Ureterolysis • Renal failure

\begin{abstract}
Background/Aims: Retroperitoneal fibrosis (RPF) is a chronic inflammatory disorder causing obstructive nephropathy and renal failure. We reviewed our management of this condition. Method: All patients with RPF treated at a single center over a 15-year period were identified. A full review of notes and computer records was undertaken. Results: Data was available on 27 patients, 3 of which were excluded from later analysis. Diagnosis was based on clinical history and cross-sectional imaging. Retroperitoneal biopsy was undertaken in 3 patients. $96 \%$ had significant renal impairment at presentation with a mean serum creatinine of $688 \mu \mathrm{mol} / \mathrm{l}$. $46 \%$ required emergency hemodialysis. All patients were treated with a combination of ureteric stents and/or steroids with an excellent clinical response. The mean best creatinine reached by the cohort was $136 \mu \mathrm{mol} / \mathrm{l}$, and renal function remained stable in the long term. No patients required chronic dialysis. Ureteric stents were removed within 12 months and low-dose steroids were continued for a mean of 34 months. Recurrent disease was observed in $25 \%$ of patients, who all responded well to further steroid therapy. Mean duration of follow-up was 76 months. Conclusions:
\end{abstract}

\section{KARGER}

Fax +41613061234

E-Mail karger@karger.ch

www.karger.com (c) 2008 S. Karger AG, Basel

$1660-2110 / 08 / 1083-0213 \$ 24.50 / 0$

Accessible online at:

www.karger.com/nec
RPF is very effectively treated by a combination of ureteric stents and steroids, with excellent long-term results using this approach. Continued follow-up is advised because of the possibility of recurrent disease.

Copyright $\odot 2008$ S. Karger AG, Basel

\section{Introduction}

Retroperitoneal fibrosis (RPF) describes a chronic inflammatory process of the retroperitoneum, with eventual fibrosis and entrapment of the ureters and other intra-abdominal organs. Ureteric involvement causes an obstructive nephropathy and the process leads to endstage renal failure if left unchecked. It may present as a result of chronic symptoms, or acutely with oligo-anuric acute renal failure, and remains a rare condition that is easily missed. Chronic periaortitis is occasionally used as an umbrella term to include RPF and inflammatory aneurysms of the abdominal aorta - for a full discussion of definitions, see Vaglio et al. [1].

RPF was thought to arise as a result of a localised inflammatory reaction to the constituents of atherosclerotic disease within the abdominal aorta [2], but there is now increasing evidence to support the theory that the condition may represent a form of systemic small- and medium-sized vessel vasculitis [3]. In keeping with this are the
Dr. Andrew C. Fry

Department of Nephrology

Lister Hospital, Stevenage SG1 4AB (UK)

Tel. +44 1438781 174, E-Mail andyfry@doctors.org.uk 
systemic symptoms of the disease, the findings of vasculitis in the vasa vasorum of the aorta and small-to-medium-sized retroperitoneal vessels in patients with RPF $[4,5]$, and the association with various autoimmune diseases. Secondary causes include drugs (especially derivatives of ergot alkaloids - e.g. methysergide, pergolide and dopamine agonists - e.g. methyldopa), overt autoimmune disease and chronic infection (e.g. tuberculosis) [1, $6,7]$. There is also a link with asbestos exposure [8]. Malignancy causes RPF usually as a result of an intense fibrotic reaction to retroperitoneal metastases (e.g. breast, colon) or primary tumour (e.g. lymphoma, sarcoma).

RPF presents in the fifth and sixth decades, with a male-to-female ratio of approximately 2-3:1 $[6,9,10]$. Diagnosis is based upon the clinical history, with abdominal, back and flank pain predominating, plus systemic symptoms such as fevers, malaise and weight loss, laboratory investigations (often impaired renal function and elevated inflammatory markers) and the results of renal imaging. Ultrasonography (US) usually reveals bi- or unilateral hydronephrosis, prompting cross-sectional imaging with computed tomography (CT) or magnetic resonance imaging (MRI). Both demonstrate the retroperitoneal mass and can distinguish idiopathic from malignant causes, and repeat imaging at follow-up helps determine disease progression or response to treatment $[1]$.

Treatment of RPF is divided into surgical and conservative approaches. The surgical, or classical, approach involves dissection of the ureters from the fibrotic tissue (ureterolysis) to relieve obstruction, sometimes combined with omental wrapping. Steroid therapy may be used post-operatively. The conservative approach utilises the combination of ureteric stenting to relieve obstruction and steroids to reduce the inflammatory mass of RPF. Together with both these approaches runs the management of the often acutely unwell patient and consideration of underlying diagnoses. The accepted view in the past was that surgery was superior, but opinion is moving in favor of the conservative approach. We aim to encourage this with publication of our data, representing the results of long-term follow-up of 24 patients with RPF treated at a single centre.

\section{Methods}

Patients with RPF managed jointly by the nephrological and urological services at Lister Hospital between 1991 and 2006 were identified retrospectively from database entries. The following data was collected from the database and case notes: patient de- mographic details, symptoms, creatinine, erythrocyte sedimentation rate (ESR) (and C-reactive protein (CRP) if available) at presentation, when the lowest value was recorded and values at latest follow-up, need for initial haemodialysis, steroid starting dose and duration of treatment, duration of ureteric stenting (and/or nephrostomies), imaging type and findings, biopsy results (where performed), details of recurrent disease and longterm outcome. Data is complete until latest follow-up, discharge, or death, except in the case of two patients who moved away from the area.

Diagnosis of RPF was made on the basis of clinical and laboratory findings and the results of imaging (renal US and CT). Retroperitoneal biopsies were only performed in a few patients where there was doubt regarding the clinical situation and/or imaging findings. Initial treatment was with bi- or unilateral insertion of ureteric J-J stents and oral corticosteroids. The response to treatment was monitored through assessment of renal function, ESR and repeat cross-sectional imaging to detect change in size of the retroperitoneal plaque. Depending on response, the corticosteroid dose was gradually reduced and ureteric stents removed (or changed at 6-monthly intervals). Figure 1 summarises our approach to management of RPF.

\section{Results}

In total, 27 patients with RPF were identified. Of these, 2 patients (A, B) were initially diagnosed with RPF, but which was later shown to be malignant disease. Patient A underwent two retroperitoneal biopsies at the time of initial presentation because of concerns regarding the imaging findings - the first (laparoscopic) was non-diagnostic, and the second (open) demonstrated RPF. Treatment with stents and steroids caused initial improvement, but he was closely followed-up and ultimately developed lymphoma (demonstrated on a third retroperitoneal biopsy), dying 2 years after first presentation. Patient $B$ had previously undergone resection of a rectal carcinoma when he presented with bilateral hydronephrosis and acute renal failure. Although imaging with CT could not distinguish between RPF and retroperitoneal spread of rectal carcinoma, he was treated for the former but suspected of the latter, and was closely monitored, later developing overt metastatic disease and dying 2 years after his initial presentation.

One further patient, a 23-year-old female, presented with dyspnea, malaise and anuria on a 2 -year background history of asymmetrical arthropathy and was found to be in acute renal failure with a creatinine of $1,100 \mu \mathrm{mol} / \mathrm{l}$, plus CRP of $316 \mathrm{mg} / \mathrm{l}$. Imaging demonstrated bilateral hydronephrosis and RPF but she failed to improve after bilateral stent insertion and commencement of steroids, even though hydronephrosis resolved. A positive anti- 


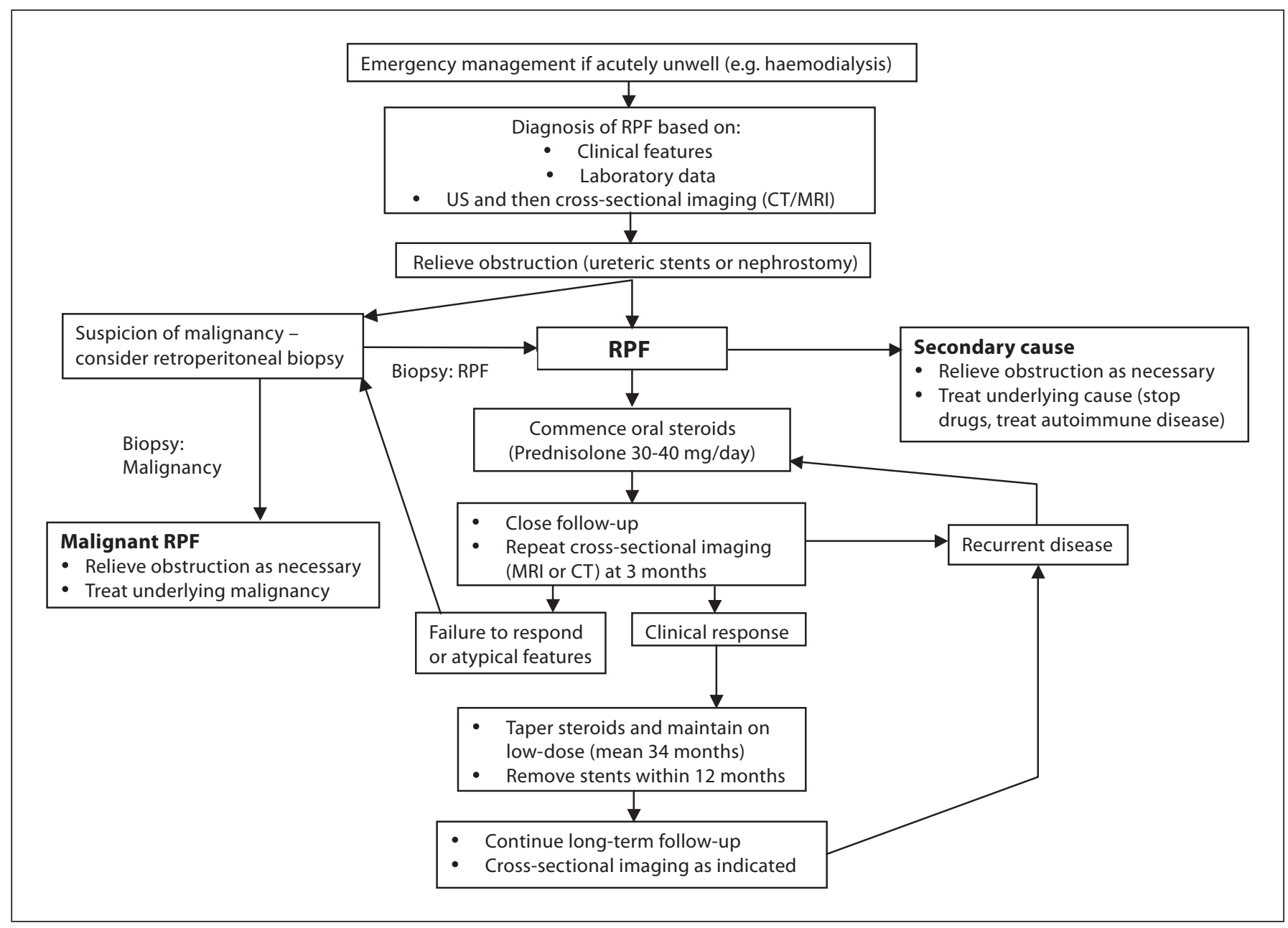

Fig. 1. Algorithm for the management of patients with retroperitoneal fibrosis (RPF). US = Ultrasound; $\mathrm{CT}=$ computed tomography; $\mathrm{MRI}=$ magnetic resonance imaging.

nuclear cytoplasmic antibody (ANCA) titre of $14 \mathrm{AU} / \mathrm{ml}$ (normal 0-7) was present (with proteinase 3 specificity) and renal biopsy was performed revealing a crescentic necrotising glomerulonephritis with severe tubulo-interstitial nephritis. A diagnosis of ANCA-positive necrotising glomerulonephritis with associated RPF was made, with dramatic improvement after the introduction of cyclophosphamide and five cycles of plasma exchange creatinine of $210 \mu \mathrm{mol} / \mathrm{l} 3$ months after her initial presentation, and $139 \mu \mathrm{mol} / \mathrm{l}$ at 1 year. Autoimmune disease was not present in any of the other patients in this study.

Further analysis is restricted to the twenty-four patients with idiopathic RPF (table 1). Twenty-two were male and 2 female, with a mean age of 63 years (range $50-77$ ) at first presentation. One patient (number 10) had been diagnosed with RPF elsewhere in 1988, and treated with stents alone (from 1988 to 1992) until problems with recurrent disease in 1995. The single most common presenting symptom was abdominal, flank or back pain, present in $58 \%$ of the cases. All patients underwent renal tract US and CT at the time of initial presentation. Eight also had renal MRI, usually as part of follow-up. Fifteen patients exhibited bilateral hydronephrosis, with unilateral hydronephrosis in 7, all of whom had contralateral abnormal kidneys (either atrophic or absent on US). Two patients had no hydronephrosis on US but demonstrated RPF on CT. Three of the patients underwent a biopsy at the time of initial presentation - diagnostic in $2 / 3$. One (number 7) underwent a biopsy later when disease recurred (diagnostic of RPF). 
Table 1. Details of the 24 patients with idiopathic retroperitoneal fibrosis

\begin{tabular}{|c|c|c|c|c|c|c|c|c|c|c|c|}
\hline $\begin{array}{l}\text { Patient } \\
\text { number }\end{array}$ & Gender & $\begin{array}{l}\text { Age at } \\
\text { presen- } \\
\text { tation } \\
\text { years }\end{array}$ & $\begin{array}{l}\text { Creatinine } \\
\text { at presen- } \\
\text { tation } \\
\mu \mathrm{mol} / \mathrm{l}\end{array}$ & $\begin{array}{l}\text { Best } \\
\text { creatinine } \\
\mu \mathrm{mol} / \mathrm{l}\end{array}$ & $\begin{array}{l}\text { Time to best } \\
\text { creatinine } \\
\text { months }\end{array}$ & $\begin{array}{l}\text { Latest } \\
\text { recorded } \\
\text { creatinine } \\
\mu \mathrm{mol} / \mathrm{l}\end{array}$ & $\begin{array}{l}\text { Total } \\
\text { duration of } \\
\text { follow-up } \\
\text { months }\end{array}$ & $\begin{array}{l}\text { Retrograde } \\
\text { ureteric stent? }\end{array}$ & $\begin{array}{l}\text { Stent } \\
\text { duration } \\
\text { months }\end{array}$ & $\begin{array}{l}\text { Number } \\
\text { of dialysis } \\
\text { sessions }\end{array}$ & Comments \\
\hline 1 & M & 65 & 322 & 100 & 55 & 115 & 59 & yes & 8 & & \multirow{24}{*}{$\begin{array}{l}\text { died } \\
\text { recurrence } \times 1 \\
\text { recurrence } \times 1 \\
\text { multiple recur- } \\
\text { rences } \\
\text { lost to follow- } \\
\text { up }(\text { emigrated) } \\
\text { recurrence } \times 1 \\
\text { died } 10 \text { years } \\
\text { later } \\
\text { died } \\
\text { recurrence } \times 1 \\
\text { died } \\
\text { died }\end{array}$} \\
\hline 2 & M & 72 & 291 & 150 & 50 & 150 & 50 & yes & 13 & & \\
\hline 3 & M & 66 & 894 & 184 & 136 & 223 & 164 & $\begin{array}{l}\text { yes } \\
\text { (after PCN) }\end{array}$ & 21 & 1 & \\
\hline 4 & M & 76 & 878 & 170 & 20 & 239 & 119 & $\mathrm{PCN}$ & 0 & & \\
\hline 5 & M & 72 & 585 & 96 & 41 & 139 & 62 & yes & 43 & 2 & \\
\hline 6 & M & 37 & 918 & 91 & 133 & 95 & 147 & yes & 14 & 3 & \\
\hline 7 & M & 50 & 1,242 & 78 & 60 & 88 & 98 & yes & 7 & 2 & \\
\hline 8 & M & 50 & 895 & 89 & 16 & 101 & 151 & yes & 5 & 1 & \\
\hline 9 & M & 62 & 820 & 321 & 3 & 328 & 12 & yes & 12 & & \\
\hline 10 & M & 59 & 418 & 80 & 127 & 91 & 160 & yes & 50 & & \\
\hline 11 & M & 61 & 345 & 87 & 112 & 87 & 112 & no (failed) & 0 & & \\
\hline 12 & M & 56 & 378 & 85 & 106 & 85 & 106 & no & 0 & & \\
\hline 13 & M & 77 & 574 & 147 & 67 & 178 & 82 & yes & 13 & 3 & \\
\hline 14 & M & 62 & 248 & 89 & 73 & 89 & 73 & yes & 5 & & \\
\hline 15 & M & 74 & 693 & 158 & 12 & 158 & 12 & yes & 8 & & \\
\hline 16 & $\mathrm{M}$ & 45 & 85 & 79 & 18 & 79 & 18 & no & 0 & & \\
\hline 17 & $\mathrm{~F}$ & 67 & 512 & 147 & 10 & 196 & 93 & yes & 10 & 2 & \\
\hline 18 & $\mathrm{~F}$ & 62 & 485 & 76 & 15 & 76 & 15 & yes & 7 & & \\
\hline 19 & M & 61 & 922 & 89 & 47 & 106 & 74 & yes & 10 & 5 & \\
\hline 20 & M & 68 & 815 & 210 & 48 & 259 & 55 & yes & 2 & & \\
\hline 21 & M & 76 & 1,184 & 355 & 11 & NK & 15 & yes & NK & 3 & \\
\hline 22 & $\mathrm{M}$ & 68 & 1,261 & 162 & 1 & 162 & 1 & yes & still in & 3 & \\
\hline 23 & M & 63 & 1,439 & 114 & 42 & 144 & 73 & yes & 8 & 5 & \\
\hline 24 & $\mathrm{M}$ & 70 & 315 & 104 & 7 & 115 & 10 & yes & 12 & & \\
\hline
\end{tabular}

$\mathrm{PCN}=$ Percutaneous nephrostomy; NK = not known.

All patients except one had significant renal impairment at the time of presentation, with a mean serum creatinine of $688 \mu \mathrm{mol} / \mathrm{l}$ (range $85-1,439 \mu \mathrm{mol} / \mathrm{l}$ ). Eleven (46\%) required acute haemodialysis, with a mean of three dialysis sessions necessary (range 1-5). Mean ESR at presentation was $79 \mathrm{~mm} / 1 \mathrm{st} \mathrm{h}$. C-reactive protein (CRP) values are available from 9 of 24 patients at the time of presentation; the mean value was $81 \mathrm{mg} / \mathrm{l}$. (Follow-up CRP data was not available.)

Twenty of 24 patients were managed by retrograde uni- or bilateral J-J stent insertion - depending on whether hydronephrosis was uni- or bilateral. Only 1 of these followed an initial percutaneous nephrostomy. Of the 4 remaining patients, 1 had a nephrostomy only for a short period of time, and retrograde stent insertion was attempted but failed in 1 patient who avoided further procedures through improvement on steroids alone. Two patients were never stented - both because of a lack of hydronephrosis on initial imaging: 1 had normal renal function, and both had already commenced steroids.

Twenty-two patients were treated with steroids from the time of initial presentation, with 1 further patient commencing steroids later because of disease recurrence. The mean starting dose of prednisolone was $30 \mathrm{mg}$ daily. In those patients who finished steroids during the course of the study - and in whom full data are available $(13 / 24)$ - the mean duration of steroids was 34 months. Two of these patients later had a recurrence. Five patients 


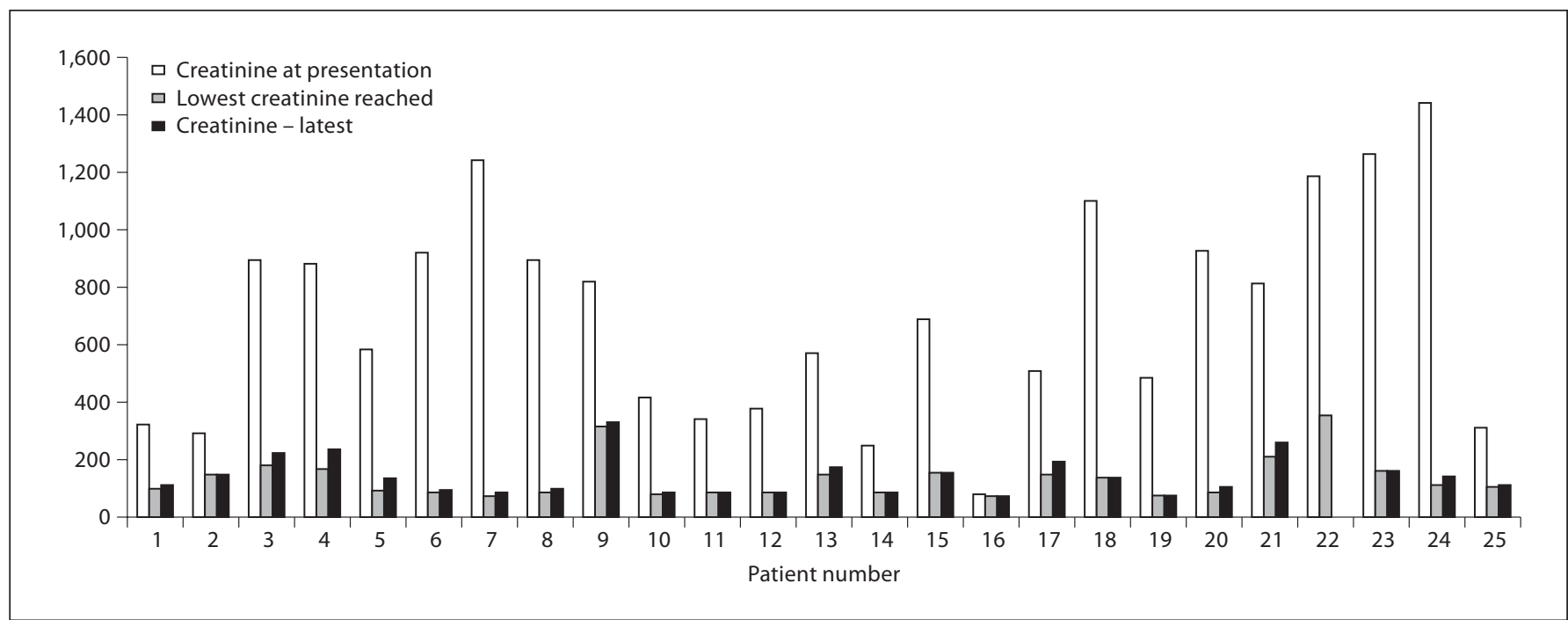

Fig. 2. Improvement in creatinine from presentation to lowest value recorded (mean of 50 months) and latest figure (mean of 76 months follow-up). Renal function remains extremely stable over time.

continue on steroids; 2 on long-term low dose because of recurrence, 1 because of an impaired short-synacthen response, and 2 are still in the process of the dose being tapered.

Clinical response to stenting and steroids was generally excellent, as evidenced by the minimal dialysis requirement even amongst those patients presenting with profound renal impairment. Renal function and ESR improved in all patients. No patients needed continued dialysis or had problems with worsening renal function in the long term, such that dialysis was required. The mean lowest creatinine value reached was $136 \mu \mathrm{mol} / \mathrm{l}$ (at 50 months (range 1-136) from initial presentation) (fig. 2). Renal function then remained stable with a mean value of $144 \mu \mathrm{mol} / \mathrm{l}$ (range 76-328) at latest follow-up. Average length of follow-up was 76 months (range 1-164). The lowest ESR had a mean value of 13 (range 1-30) and was reached 44 months after initial presentation (range 1139). Stents were kept in situ for a mean of 12 months (range 2-50) and changed approximately every 6 months, where necessary. One patient had problems with stent obstruction and required long-term percutaneous nephrostomies.

One patient underwent bilateral ureterolysis whilst undergoing elective AAA repair at another centre, his ureteric obstruction having been managed successfully through stents and steroids until this point. No other patients underwent ureterolysis.

Use of Steroids and Ureteric Stents in Retroperitoneal Fibrosis
Eighteen patients remained in remission for the duration of their follow-up, as defined by continuation of stable renal function, persistent normalisation of inflammatory markers and the lack of any new symptoms. Disease recurred in 6 , with a mean time to recurrence of 52 months after initial presentation (range 7-115), and a mean of 15 months after steroid withdrawal. Recurrence was noticed through a combination of worsening renal function (mean creatinine before and at recurrence 125 and $215 \mu \mathrm{mol} / \mathrm{l}$, respectively, although a significant rise in creatinine was seen in only $50 \%$ of patients), ESR (mean 34 at recurrence) or repeat imaging (usually CT). Five of 6 patients had a combination of factors indicating recurrence - but in 1 (number 7) it was only demonstrated by surveillance CT. Steroids were restarted in 3 patients, started for the first time in 1 and increased in 1 - the only patient who also required repeat stenting. One patient had multiple episodes of recurrence, usually diagnosed by a rising ESR or repeat CT, but he remains well with a creatinine of $101 \mu \mathrm{mol} / 113$ years on from his initial presentation. Recurrence of RPF was suspected on the basis of CT findings in patient 7 , who was at this stage under the care of another centre. He underwent a biopsy which demonstrated RPF, but steroids were not restarted given his normal renal function and inflammatory markers and he remains well 4 years later. There was no significant morbidity as a result of recurrent disease in any patient.

Nephron Clin Pract 2008;108:c213-c220 
Six patients died: all male, with an average age of 77 years (range 71-84 years) and mean of 7 years from diagnosis of RPF (range 1-17). Cause of death was unrelated to RPF in all except patient 21 , who died aged 78 as a result of pyelonephritis and systemic sepsis, in the context of significant medical co-morbidity. His renal impairment had improved dramatically with stenting and steroids, but recurrent problems with infection and obstruction necessitated conversion to nephrostomies. In the other 5 , 2 died from carcinoma of the lung, 1 from congestive cardiac failure, with unknown cause in 2 . Two patients were lost to follow-up; 1 after 12 months (emigrated) and 1 after 1 month (returned to native country).

\section{Discussion}

We have demonstrated that retroperitoneal fibrosis can be effectively managed using the conservative strategy of ureteric stenting and oral steroids, without requiring surgery and ureterolysis. The demographics of our cohort were similar to other published data, though with a higher predominance of male patients [1]. Where our data does differ is in the severity of renal impairment at presentation - $96 \%$ had significant renal impairment, with a mean serum creatinine of $688 \mu \mathrm{mol} / \mathrm{l}$. This is worse than in other recent studies, in which typically 50 $75 \%$ of patients had renal impairment, itself also less severe than in our cohort $[5,11-14]$.

Half of our cohort required acute haemodialysis when first presenting, the indication for dialysis following standard criteria such as fluid overload and/or hyperkalaemia [15]. This compares to only 1 patient in 22 in the cohort of van Bommel et al. [13]. The severity of renal failure is presumably due to selection bias, in that those patients with renal impairment and/or evident obstruction are referred to the nephrology or urology departments, and patients with RPF but no renal abnormalities may be managed by general physicians or rheumatologists (as was the case initially with patient 16).

With hydronephrosis secondary to RPF demonstrated by cross-sectional imaging, we aim for early relief of obstruction - as soon as the patient is medically stable and can tolerate urinary tract instrumentation under sedation or anaesthesia. Retrograde insertion of J-J stents was possible in 19 of 20 cases when used as the initial means of relieving obstruction. Only very occasionally was percutaneous nephrostomy necessary, usually because of problems with the patient's fitness for general anaesthesia.
The first use of oral steroids in the treatment of RPF was described in 1958 [16]. Our starting dose of approximately $30 \mathrm{mg} /$ day is at the lower range of that recommended or utilised in recent literature (generally 30-60 $\mathrm{mg} /$ day) $[1,6,11,13]$. Our policy is to then reduce this over 1-2 months to approximately $10 \mathrm{mg} /$ day and then more gradually, provided remission is maintained. $\mathrm{Pa}$ tients in remission are kept on low-dose steroids (5 mg/ day or less) for 2-3 years, perhaps a slightly longer duration than reported elsewhere (see below) $[1,6,13]$. Only a small number of patients remain on low-dose steroids in the very long term. Proton-pump inhibitors and bisphosphonates are routinely prescribed to reduce gastric and bone side effects of steroid use, but data was not collected on any long-term complications of steroid therapy. Ureteric stents are replaced or removed according to clinical response and repeat imaging.

All our patients responded dramatically to stent insertion and steroid therapy, demonstrated by the need for only three dialysis sessions on average in a patient cohort with significant renal impairment and associated metabolic derangement at presentation. Increased levels of inflammatory markers also resolved. The improvement in renal function was maintained in the long term, even if disease recurred. With an average of six years follow-up per patient, none have required further renal replacement therapy. This excellent short- and long-term outcome argues strongly in favour of the conservative approach; similar results have been reported elsewhere. Ilie et al. [11] demonstrated successful treatment of 28 cases with stents and steroids, with improvement or maintenance of normal renal function in $96 \%$, and Higgins et al. [17] presented 17 cases of RPF, 13 of which were treated primarily with steroids with good results. Van Bommel [6] found 147 cases from the literature treated primarily with steroids, with good results reported in $83 \%$ and recurrence in $16 \%$, and reported a good outcome in $89 \%(19 / 21)$ of his own patient series, again treated primarily with steroids.

The surgical approach to the treatment of RPF involves laparotomy, biopsy, ureterolysis and omental wrapping of the involved ureter(s). Laparoscopic biopsy and ureterolysis are also possible $[18,19]$. The ability to obtain a tissue diagnosis - and exclude malignancy - is one of the reasons commonly cited as an indication for this approach. There are a number of counter arguments, not least the low incidence of malignancy in suspected RPF. In a 1977 review of 481 cases of RPF, before the routine use of CT scanning, the rate of malignancy was found to be only $8 \%$ [10]. Biopsies are still fallible and may miss 
malignancy [20], as shown by our data - biopsy was nondiagnostic in $1 / 3$ cases of RPF, and falsely negative (twice) in the patient with eventual lymphoma. The sophistication of cross-sectional imaging with CT (or MRI) is such that non-malignant RPF can normally be distinguished from malignancy $[1,21]$. There is also a prior history of malignancy in most patients with malignant RPF, and a recent review article was able to state that 'a careful search for (occult) malignancy and intelligent use of CT will provide an accurate diagnosis in nearly every case' [6]. If diagnostic doubt remains, close follow-up with repeat imaging is advised.

In addition to malignancy, one must also consider other secondary causes of RPF, particularly if there is failure of the expected response to relief of obstruction and introduction of steroids - demonstrated by the patient with ANCA-positive glomerulonephritis. Atypical features should also alert one to the presence of a secondary cause - this individual was female, much younger and had a far higher CRP than the rest of the cohort, in addition to a history of arthropathy. In a recent study of 16 consecutive patients with chronic periaortitis, 3 had rapidly-progressive renal impairment in association with both ANCA positivity and hydronephrosis, and another 10 were positive for other autoantibodies (usually antinuclear antibody) [4]. The overt presence of autoimmune disease may signal the need for more intensive immunosuppression, depending on the clinical situation.

Ureterolysis can be associated with considerable morbidity. Cooksey et al. [22] followed-up 21 patients treated by ureterolysis and reported 1 post-operative death, 3 patients with ureteric leaks and 3 with intestinal obstruction. In another group of 7 patients treated by ureterolysis there was 1 post-operative death from pneumonia, 2 ureteric leaks and 1 post-operative ileus requiring surgical decompression [23]. Mundy et al. [24] found 67 post-operative complications in 26 out of 36 patients who underwent ureterolysis for RPF. This high incidence of complications is perhaps unsurprising given the likelihood of co-existent renal failure and prevalence of co-morbidity, and further illustrates the benefits of the conservative approach. The technique of laparoscopic ureterolysis may be associated with a reduction in morbidity [25].

RPF often recurs after initial treatment. A clue as to the presence of recurrence is normally provided by a rise in ESR, serum creatinine or the presence of symptoms, prompting repeat imaging. We found a recurrence rate of $24 \%$, slightly higher than that often reported for treatment with steroids, which may reflect the severity of disease in our cohort. From the literature, recurrence rates of approximately $50 \%$ are seen after treatment with ureterolysis, and about $10 \%$ if patients are treated with steroids $[1,6,21,22,26]$. Recurrence is reported to normally occur within the first year after diagnosis, but our data differs in this respect, with recurrence in only 1 patient during this period and a much longer mean time to recurrence of 52 months after initial presentation. We ascribe this result to our policy of continuing steroids at a low dose for a few years. This is likely to explain the difference between our results and those of van Bommel et al. [13], who demonstrated a very high incidence of recurrence at $72 \%$; but steroids were withdrawn in their patients at 1 year. Disease recurrence was easily and effectively managed by the reintroduction - or increased dose - of steroids, and rarely required repeat stent insertion. We did not need to use any additional immunosuppressive therapy beyond corticosteroids. This held true even for multiple episodes of recurrence. Perhaps the most important practice point is the necessity of continued monitoring of patients judged to be in remission.

Other immunosuppressive strategies for treating idiopathic RPF have been proposed, including azathioprine, cyclosporin, cyclophosphamide, methotrexate and mycophenolate mofetil, or hormonal manipulation with tamoxifen [6, 21, 27-29]. Moroni et al. [12] compared three groups, treated with steroids plus ureterolysis, azathioprine or tamoxifen, and found little difference between them, although numbers were limited (17 patients in total). Warnatz et al. [14] retrospectively analysed surgery and/or immunosuppression for the treatment of 20 patients with RPF or inflammatory aortic aneurysms and concluded that immunosuppression was an effective treatment for RPF, but regimes were varied and no clear conclusions could be drawn as to which was of most benefit. Based on our results, and the current literature, we do not feel that at present there is evidence to select any other immunosuppressant over steroid therapy.

This study is retrospective, observational and reflects only the experience of a single centre. However, it provides reassurance that our approach to management of this condition is correct, and compares favourably with other - all similarly sized - studies in the literature. Whilst the time-scale over which the study was performed is lengthy, this reflects the relative scarcity of the condition, even in a tertiary referral unit. Both KF and TM were involved in the management of these patients from the outset, providing a consistency of approach. 


\section{Conclusions}

Our results augment the growing consensus that RPF can be effectively treated with ureteric stenting and steroid therapy. Current cross-sectional imaging techniques and a degree of clinical suspicion are effective at identifying malignant disease, and biopsy should only be considered in a minority of cases. All our patients initially re- sponded to this approach, with remarkable improvement in renal function despite severe renal impairment at presentation, and none have since progressed to end-stage renal failure. The need for long-term follow-up should be emphasised as recurrence can occur, although this responds well to further steroid therapy. Effective management of the condition requires close collaboration between nephrologists, urologist and radiologists.

\section{References}

1 Vaglio A, Salvarani C, Buzio C: Retroperitoneal fibrosis. Lancet 2006;367:241-251.

$\checkmark 2$ Mitchinson MJ: Chronic periaortitis and periarteritis. Histopathology 1984;8:589600.

3 Jois RN, Gaffney K, Marshall T, Scott DG: Chronic periaortitis. Rheumatology (Oxford) 2004;43:1441-1446.

$\checkmark 4$ Vaglio A, Corradi D, Manenti L, Ferretti S, Garini G, Buzio C: Evidence of autoimmunity in chronic periaortitis: a prospective study. Am J Med 2003;114:454-462.

5 Corradi D, Maestri R, Palmisano A, Bosio S, Greco P, Manenti L, Ferretti S, Cobelli R, Moroni G, Dei Tos AP, Buzio C, Vaglio A: Idiopathic retroperitoneal fibrosis: clinicopathologic features and differential diagnosis. Kidney Int 2007;72:742-753.

-6 van Bommel EF: Retroperitoneal fibrosis. Neth J Med 2002;60:231-242.

7 Greco P, Vaglio A, Corradi D, Cobelli R, Zompatori M, Buzio C: Tuberculosis as a trigger of retroperitoneal fibrosis. Clin Infect Dis 2005;41:e72-e75.

$>8$ Uibu T, Oksa P, Auvinen A, Honkanen E, Metsarinne K, Saha H, Uitti J, Roto P: Asbestos exposure as a risk factor for retroperitoneal fibrosis. Lancet 2004;363:1422-1426.

9 Baker LRI, Mallinson WJ, Gregory MC, Menzies EA, Cattell WR, Whitfield HN, Hendry WF, Wickham JE, Joekes AM: Idiopathic retroperitoneal fibrosis: a retrospective analysis of 60 cases. Br J Urol 1987;60: 497-503.

10 Koep L, Zuidema GD: The clinical significance of retroperitoneal fibrosis. Surgery 1977;81:250-257.
1 Ilie CP, Pemberton RJ, Tolley DA: Idiopathic retroperitoneal fibrosis: the case for nonsurgical treatment. BJU Int 2006;98:137-140.

12 Moroni G, Gallelli B, Banfi G, Sandri S, Messa P, Ponticelli C: Long-term outcome of idiopathic retroperitoneal fibrosis treated with surgical and/or medical approaches. Nephrol Dial Transplant 2006;21:2485-2490.

13 van Bommel EF, Siemes C, Hak LE, van der Veer SJ, Hendriksz TR: Long-term renal and patient outcome in idiopathic retroperitoneal fibrosis treated with prednisone. Am J Kidney Dis 2007;49:615-625.

14 Warnatz K, Keskin AG, Uhl M, Scholz C, Katzenwadel A, Vaith P, Peter HH, Walker UA: Immunosuppressive treatment of chronic periaortitis: a retrospective study of 20 patients with chronic periaortitis and a review of the literature. Ann Rheum Dis 2005;64:828-833.

15 Fry AC, Farrington K: Management of acute renal failure. Postgrad Med J 2006;82:106116.

16 Ross JC, Tinckler LF: Renal failure due to peri-ureteric fibrosis. Br J Surg 1958;46:5862.

17 Higgins PM, Bennett-Jones DN, Naish PF, Aber GM: Non-operative management of retroperitoneal fibrosis. Br J Surg 1988;75: 573-577.

18 Okumura A, Murakami K, Nozaki T, Fuse H: Laparoscopic ureterolysis for idiopathic retroperitoneal fibrosis. Int J Urol 2005;12: 1079-1081.

19 Fugita OE, Jarrett TW, Kavoussi P, Kavoussi LR: Laparoscopic treatment of retroperitoneal fibrosis. J Endourol 2002;16:571-574.

20 Higgins PM, Aber GM: Idiopathic retroperitoneal fibrosis: an update. Dig Dis 1990;8: 206-222.
21 Marcolongo R, Tavolini IM, Laveder F, Busa M, Noventa F, Bassi P, Semenzato G: Immunosuppressive therapy for idiopathic retroperitoneal fibrosis: a retrospective analysis of 26 cases. Am J Med 2004;116:194-197.

22 Cooksey G, Powell PH, Singh M, Yeates WK: Idiopathic retroperitoneal fibrosis: a longterm review after surgical treatment. $\mathrm{Br} J$ Urol 1982;54:628-631.

23 van Bommel EF, van Spengler J, van der Hoven B, Kramer P: Retroperitoneal fibrosis: report of 12 cases and a review of the literature. Neth J Med 1991;39:338-345.

24 Mundy AR, Kinder CH, Flannery JF, Joyce MR: Hypertension and thromboembolism in idiopathic retroperitoneal fibrosis. $\mathrm{Br} \mathrm{J}$ Urol 1982;54:625-627.

25 Elashry OM, Nakada SY, Wolf JS Jr, Figenshau RS, McDougall EM, Clayman RV: Ureterolysis for extrinsic ureteral obstruction: a comparison of laparoscopic and open surgical techniques. J Urol 1996;156:1403-1410.

26 Wagenknecht LV, Hardy JC: Value of various treatments for retroperitoneal fibrosis. Eur Urol 1981;7:193-200.

-27 van Bommel EF, Hendriksz TR, Huiskes AW, Zeegers AG: Brief communication: tamoxifen therapy for nonmalignant retroperitoneal fibrosis. Ann Intern Med 2006; 144:101-106.

28 Puce R, Porcaro AB, Curti P, Girelli D, Pantalena M, Malossini G, Tallarigo C: Treatment of retroperitoneal fibrosis with tamoxifen: case report and review of literature. Arch Esp Urol 2000;53:184-190.

29 Marzano A, Trapani A, Leone N, Actis GC, Rizzetto M: Treatment of idiopathic retroperitoneal fibrosis using cyclosporin. Ann Rheum Dis 2001;60:427-428. 